\title{
Microbiota and their Influence in the Human Body
}

\author{
Awatif Abid Al-Judaibi \\ Faculty of Science, Department of Biological Sciences, Microbiology Section, Jeddah University, P.O. Box: \\ 13520, Jeddah 21414, Saudi Arabia.
}

\begin{abstract}
Scientists have invested considerable resources in the study of the microbiota of the human body. These microorganisms play pivotal roles in immunity and disease. Of which, probiotics are live beneficial microorganisms that keep your intestinal or lung microbiota healthy, and occupy a special role in combating the infections. Thus, it is critical to understand their contributions to these processes. Technology can facilitate advanced studies of the microbiota, including how it develops and its positive and negatives effects on the immune system. This paper investigates how several factors (e.g. birth delivery mode, metabolic activities, types of microorganisms, and immune system interactions) affect the microbiota, particularly in early life. The paper also discusses how gastrointestinal microbes in particular may be associated with certain disease processes, such as those related to schizophrenia, autism, and diabetes. Clinical studies show that certain probiotic strains, like Lactobacillus rhamnosus GG and Bifidobacterium animalis ssp. lactis help to prevent infection of pathogenic organisms (both bacterial and viral). This research may yield crucial contributions to disease prevention and public health. The dysbiosis may result in changes in the acquired immunity later on. The probiotic strains can prevent viral replication during SARS-CoV-2 or COVID-19 infection by reducing proinflammatory cytokines. There has been much interest into the intestinal flora as proposed by the diversity, volume, and proposed role in disease. Future research in the field of microbiome should be done in order to uncover their association to gut virome by noting both their influence on each other and relevant health and disease.
\end{abstract}

Keywords: COVID-19, Microbiota, Immune system, Crohn's disease, Schizophrenia

*Correspondence: aaaljudaibi@uj.edu.sa; +966 505660345

(Received: September 23, 2020; accepted: Feburary 04, 2021)

Citation: Al-Judaibi AA. Microbiota and their Influence in the Human Body. J Pure App/ Microbiol. 2021;15(1):42-52. doi:10.22207/ JPAM.15.1.27

(c) The Author(s) 2021. Open Access. This article is distributed under the terms of the Creative Commons Attribution 4.0 International License which permits unrestricted use, sharing, distribution, and reproduction in any medium, provided you give appropriate credit to the original author(s) and the source, provide a link to the Creative Commons license, and indicate if changes were made. 


\section{INTRODUCTION}

One of the most important symbiotic relationships in human beings involves the microbiota of the body, particularly in the intestinal tract. These benefits-and occasional negative effects-begin at the time of formation of the microbiota and continue until death. Many studies over the last century have shown the importance of the microbiota in humans, which begins forming in infancy and develops rapidly until the age of 2-3 years. During this period, the microbiota stabilises and forms the composition that will persist into adulthood ${ }^{1-2}$.

The microbiota affects early development of the immune system and offers long-term benefits to human health by providing antigens and antibodies that strengthen immunity. It also affects the development of distal organs, thus impacting the human body at the systemic level $\left.\right|^{3-5}$. Studies have shown that the microbiota is involved in immune responses to various pathologies, such as high blood pressure, diabetes, and psychological diseases $s^{6-10}$. For example, faecal microbiota transplants have shown promising results for treating chronic gastrointestinal diseases and autism spectrum disorders ${ }^{11-13}$. Other studies highlight the benefit of the microbiota in preventing or minimizing viral infections, including norovirus and coronaviruses ${ }^{14-16}$. In this review article, we discuss the importance of microbiota in treating, preventing, and reducing pathogenic disease, including viral diseases such as COVID-19.

\section{Formation of Microbiota}

Microbiota begin forming in utero, where the mother's gut and placenta play critical roles ${ }^{17-18}$. Factors that influence this process include the type of delivery (e.g. vaginal or Caesarean), the mother's lifestyle (e.g. diet and other habits) and health history (e.g. illness, antibacterial medications $)^{19-23}$. The dominant bacterial forms in an embryo include Lactobacillus and Escherichia coli $i^{24}$. These microbes mostly colonize the gut of the foetus and can influence immunity and disease risk ${ }^{25}$.

After delivery, a rapid shift in the microbiota composition occurs, and this shift depends on several factors, such as the delivery mode and feeding patterns of the infant ${ }^{26-27}$. The delivery method has significant implications on newborns' microbiota formation ${ }^{28}$. For instance, children who are born vaginally have higher levels of Lactobacilli than those born surgically, perhaps due to the abundance of Lactobacilli in the vagina ${ }^{24}$. In contrast, children born via Cesarian section harbour less diverse microbiota, and normal colonization takes longer in these infants ${ }^{29-30}$. The most abundant microorganisms in babies born via C-section include the Bacteroides genus and other facultative anaerobic bacteria, such as the Clostridium species ${ }^{31}$. Compared to $72 \%$ of children born vaginally, only $41 \%$ of infants born via C-section exhibit a similar faecal structure to that of their mother ${ }^{32-33}$.

During the first month, the microbiota in a new-born is purely aerobic, limited in numbers, and low in diversity ${ }^{34}$. After one month, the microbiota becomes anaerobic, allowing the growth of other bacterial forms $\mathrm{s}^{35}$. Several factors can affect this change, including antibiotic treatments, diet, and illness. In the first year, conditions in the body determine the growth and diversity of its microbiota ${ }^{36-37}$. Initially, the microbiota is mainly limited to two main bacterial phyla: Proteobacteria and Actinobacteria ${ }^{33}$. By about two years of age, however, the child's microbial composition resembles that of an adult. This process is particularly affected by the introduction of solid foods around six months of age $^{38}$. The microbiota continues to develop into adulthood. The composition changes, shifting more to Clostridium and Bacteroidetes species. Other life events, such as illness, also affect the microbiota $^{31.39}$.

\section{Benefits of the Microbiota}

The microbiota protects the body from diseases and enhances metabolic activities. These microorganisms have important functions in the skin, oral cavity, gut, reproductive tract, and nasal cavity ${ }^{40-41}$. The skin hosts a wide diversity of beneficial microbes that provide physical and immunological protection from pathogens. For example, Staphylococcus epidermidis is a common protective microbe on the skin that produces bacitracin, a toxic substance that acts as an antibiotic, ensuring that other harmful bacteria do not enter the body ${ }^{42-43}$. Enforcing constant use of antibiotics to treat severe infections like COVID-19 in hospitals can eventually lead to the antibiotic resistance. Phage therapy will help control diseases involving antibiotic resistance. 
This is an insight into use of bacteriophages to control COVID-19 in a post-treatment-control era $^{44}$. Research shows that other microorganisms enhance the activities of T cells by increasing their ability to respond to pathogenic microorganisms ${ }^{45}$. Thus, researchers discovered that phages targeting B16 melanomas in mice attracted tumor-associated macrophages to the tumor, which led to tumor regression and prolonged survival in mice ${ }^{46}$.

The microbiota of the gastrointestinal tract contributes to metabolism, neuronal development, and physiology ${ }^{47}$. The human gut hosts approximately 400-1,000 microbial species that participate in digestion, nutrient absorption, and protection against pathogenic microbes. Some of these species help strengthen and maintain the mucosal barrier, which protects cells from acids in the stomach and other digestive enzymes. In addition to their role in digestion, gut microbes interact with the mucosal immune system to facilitate disease detection and management ${ }^{48-49}$. They also contribute to enzyme production. For example, bacteria in the colon act as enzymes to facilitate fermentation of carbohydrates into metabolites ${ }^{50}$. Different microbes in the gut produce propionate, acetate, and butyrate enzymes, which assist in apoptosis, differentiation, gene expression, and proliferation of epithelial cells ${ }^{51}$. Thus, the microbiota of the digestive tract has significant implications for immunity, digestion, cell development, and pathogenesis.

The reproductive system depends on a healthy microbiota. For instance, the female reproductive system has different microorganisms that participate in various aspects of fertility, such as menstruation, gametogenesis, pregnancy, and childbirth $^{52}$. These microbiota boost immunity by preventing diseases, including HIV, urinary tract infections, yeast infections, sexually transmitted diseases, and bacterial vaginosis ${ }^{53}$. In contrast to the female system, the upper parts of the male urinary tract do not have microbiota, although the lower genital region does ${ }^{54}$. Dysbiosis could potentially contribute to a contributing cause of gut infection. It is difficult to know the connection between the gut and lung microbiome. Acute lung injury, mediated by gut microbiota, was associated with a shift in the microbial community in the lung, showing a co-relation between gut and lung ${ }^{55}$. These strains exhibit anti-tumor or immunomodulating activities, and some of them have also shown inhibitory effects on viruses ${ }^{56}$.

Finally, the body's microbiome influences mental health due to its implications in the brain. Microbes of the gut can affect brain functioning by releasing molecular substances that trigger nerves and determine behaviour ${ }^{57-58}$. Research also indicates a relationship between microorganisms in the stomach and psychological conditions, such as autism and depression ${ }^{59}$. Although microbiota often do not exhibit direct links to diseases, their regulatory roles contribute to complex pathogenesis processes ${ }^{60}$. Changes in the composition of microbes may trigger or inhibit the development of asthma, depression, allergies, metabolic disorders, and autism ${ }^{61}$. Therefore, restoring or establishing a healthy microbial composition may represent a critical step for managing these conditions. Inflammatory mediators transported from the gut to the lungs by the blood can have detrimental effects on the lungs ${ }^{62}$.

\section{Sources of the Microbiota}

The human microbiota originates from numerous sources, including diet and supplementation. For example, prebiotics are mainly non-digestible food particles that enhance the stimulation, development, and growth of different microorganisms in the colon. They enhance digestion and provide an environment where healthy microbes can thrive. Humans can obtain prebiotics from numerous dietary substances, mainly carbohydrates ${ }^{63}$. Certain foods are essential sources of prebiotics, including tomatoes, chicory, beans, wheat, sugar beets, onions, milk from cows and humans, and asparagus. According to research, breast milk supports the transfer of bacteria from the mother to child and contributes to the development of healthy microbiota in newborns ${ }^{64}$.

There are several categories of prebiotics. For example, fructans contain inulin and activate the bacteria that produce lactic acid. Scientists have found that fructans stimulate the action of other beneficial bacterial strains. Galactooligosaccharides (GOS) are a class of prebiotics that play a significant role in stimulating Lactobacilli, Firmicutes, Enterobacteria, and Bifidobacteria. Oligosaccharides, which are primary prebiotics, can be derived from starch, 
polysaccharides, glucose, and non-carbohydrate food substances ${ }^{65-66}$. In addition, they enhance immunity by improving the capacity of antibodies to respond and adapt to viral vaccinations. Studies also have shown that prebiotics reduce side effects of vaccinations ${ }^{67}$. Diet is an important and regular lifestyle element that can influence a user's gut microbes, along with its viral species ${ }^{58}$. Taking into account that the microbiota can be affected by diet, smoking, pre-and-probiotics, research continues into their use to restore health. Fermentation products of prebiotics decrease the gut $\mathrm{pH}$ which impact on the compositions and load of the intestinal microbiota ${ }^{69}$. According to results of a study in 2006, supplementation with 15 grams of FOS for 3 weeks improved Crohn's disease symptoms and bifidobacteria population in the feces ${ }^{70}$.

Probiotics are yeast or bacteria microorganisms that exhibit a positive role in the body. They can be particularly effective at restoring a microbiota that is damaged or lost due to illness or other lifestyle issues. Probiotics play a critical role in immunity by balancing harmful and healthy microbes. The two main types of probiotics are Lactobacilli and Bifidobacteria. Major sources of Lactobacilli include yogurt and other fermented foods ${ }^{71}$. These microbes improve digestion, particularly of lactose, and reduce diarrhoea. Foods that contain Bifidobacteria include yogurt, kefir, tempeh, and kimchi. These probiotic substances provide numerous benefits to the body, including the management of irritable bowel syndrome $^{72}$. The primary mechanism of probiotics is mainly due to competitive exclusion, adhesion, immunomodulation, brain-gut interaction and enzymatic activity ${ }^{73}$.

\section{The Microbiota and Age}

\section{Newborns}

In newborns, the microbiota affects the immune system and thus may help prevent disease and improve immunity. Conversely, these same interactions can become pathogenic, causing different diseases in infants. According to research, infants who are exposed to a broad range of microbes in their early years are less likely to suffer from atopic diseases ${ }^{74}$. Thus, reducing microbiota exposure during birth may help explain the increase in immunological disorders. During the early days of life, a balanced and healthy development of microbiota leads to a robust innate and adaptive immune system that can tolerate pathogens. However, imbalance and poor development of microbes can be a primary predisposing factor for autoimmune diseases and atopic infections ${ }^{75}$.

For instance, children with food allergies exhibit reduced levels of Lactobacillus and Bifidobacterium but excessive levels of enteric bacteria. Other studies indicate that newborns with protein allergies have excess Clostridium coccoides in their faecal matter ${ }^{76}$. Additionally, the incidence of inflammatory bowel disease in newborns often depends on the composition of the microbiota. Studies show that reduced diversity and composition of Bifidobacterium is common among infants with necrotizing enterocolitis, a form of inflammatory bowel disease ${ }^{77}$. Breast milk, which contains healthy microbiota, is especially critical in the prevention of diarrhoea and respiratory diseases ${ }^{78}$. Overall, the microbiota is essential for newborns' immunity and even acts as an antibiotic against pathogenic bacteria.

\section{The Elderly}

A unique interaction exists between the microbiota and immunity among the elderly. As individuals age, their immune system undergoes deregulation, which reduces their ability to respond to mitogens. Additionally, maintaining homeostasis and balanced intestinal microbes is increasingly difficult with age, making the elderly more susceptible to conditions such as Alzheimer's disease. Malnutrition and poor diet among seniors further impairs the functionality of the microbiota, especially in the gastrointestinal tract. These changes can cause diseases, such as inflammatory and autoimmune disorders. For example, Clostridium difficile is a primary bacterial cause of diarrhoea among the elderly ${ }^{79-81}$. This microbe is disproportionally present among the elderly due to environmental conditions (e.g. calorie restriction), medications (e.g. antibiotics), unhealthy intestinal microbiota, increased comorbidities, and changes in immunity. Overall, the features of the bacterium and the state of the immune system in the elderly determine the severity, mortality, and recurrence of Clostridium difficile infection in this population ${ }^{82-84}$. 


\section{The Microbiota and Disease}

Interactions between the immune system and microbiota can affect overall health. For example, some interactions lead to better disease protection, whereas others may result in disease. Common disorders in the interaction between immunity and the microbiota include Crohn's disease, schizophrenia, autism spectrum disorder, obesity, and diabetes. Since COVID-19 does not have a safe method of treatment or prevention, it is best to focus on other strategies for its treatment.

\section{Crohn's Disease}

Crohn's disease is a condition caused by a dysfunctional interaction between the microbiota and the immune system. The disease is especially common among older adults. Studies with mice have shown that the urease enzyme and microbial activities may represent a major cause of this illness ${ }^{85}$. Intestinal changes related to Crohn's disease interfere with the commensal relationship between the immune system and the gut microbiome, leading to pathological symptoms, such as inflammation of the digestive tract and tissue destruction ${ }^{86}$.

\section{Schizophrenia}

Interactions between immunity and microbiota may cause schizophrenia ${ }^{87}$. Research shows that variations in microbial diversity are likely to result in immune reactions or responses. Alternatively, microbial variations can increase production of mediators (e.g. inflammation), which then cross the brain-blood barrier and affect the brain, in turn leading to schizophrenia ${ }^{88}$. Changes in the microbiota also may activate immunity and cause schizophrenia. Immune alteration sequences can include the activation of T cells and increased activities of chemokines, phase reactants, and plasma cytokines ${ }^{89}$.

\section{Autism Spectrum Disorder}

Similar to schizophrenia, the microbiota in the digestive tract can produce metabolites that travel to the brain and affect its function. Changes in the microbiota may promote the production of metabolites that influence certain disease processes, such as those related to autism spectrum disorder. These metabolites include gamma aminobutyric acid, noradrenalin, and tryptamine ${ }^{90}$. Research also has identified excessive levels of $p$-cresol and $p$-cresyl as causes

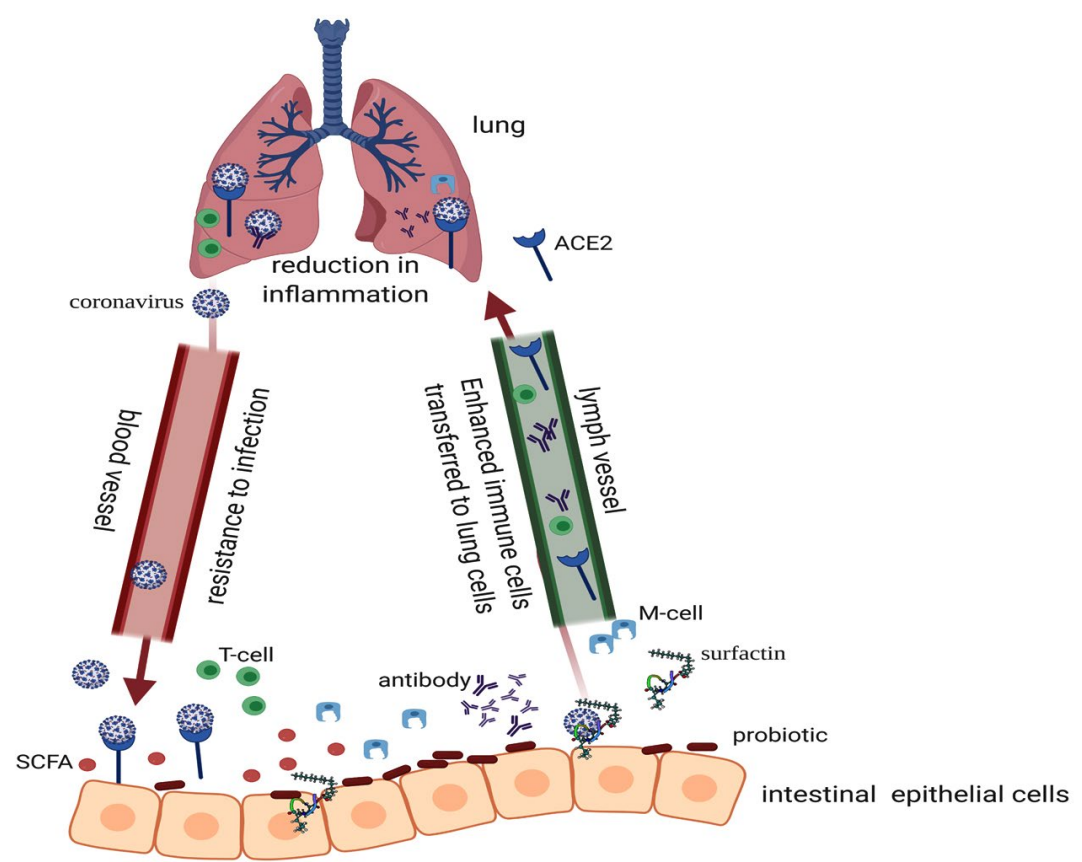

Fig. 1. The beneficial metabolites of probiotics and the enhancing antiviral immunity to provide protection to the lungs. 
of cognitive disorders and behavioural variations in children with autism spectrum disorder. Gut microbiota in these children also may lead to obesity. Microbes can influence obesity in children by affecting energy extraction from food, hormonal functions, metabolism of lipids, and immune responses $^{91-92}$.

\section{Diabetes}

Diabetes is a common condition among the elderly. The occurrence of pancreatic diseases, such as diabetes, may be synonymous with changes in the gut microbiota and in immune function. For instance, dysbiosis affects signalling pathways and reshapes the functions of the intestinal barriers. These activities have a direct implication on insulin resistance. Overall, these interactions between the immune system and microbiota vary according to age $\mathrm{e}^{93-94}$.

Microbiota influence on Viruses like SARS-CoV-2

Viral infections include the common cold and flu, as well as the recently introduced COVID-19 virus. The interplay between the environment and biological host factors, such as regulation of the antiviral immune responses via intestinal bacteria, influences the outcome of these infections. The host immune system promotes the growth of beneficial microbes along the intestinal walls by producing molecular signals that support immune cell growth and targeted responses ${ }^{95}$. Although the interactions between viruses and commensal microorganisms remain unclear, the microbiota likely has important immune system functions, including resisting viral invasions via direct and indirect mechanisms ${ }^{96}$. Also, the diversity of gut bacteria is decreased in old age, and we learn that Covid-19 has mostly a deadly impact on elderly patients, which again suggests the role played by microbiota in this particular scenario ${ }^{97}$. Recent studies demonstrate that Acinetobacter and Klebsiella bacteria have been observed in critical cases of COVID-19, who were in intensive care unit system set ${ }^{98}$. It was reported that infection with COVID-19 infection can cause detrimental effects on the gastrointestinal system tract, which lead to a severe loss of immunity after recovery ${ }^{99-100}$.

The microbiota creates disease resistance by allowing bacterial membranes to develop tolerance to the immune system through an increase in anti-inflammatory cytokines, such as interleukin-10. The gut microbiota can promote immunity against viral invasion via several mechanisms, such as binding of viruses to structural bacterial molecules. For example, the HIV-1 virus binds to lipopolysaccharides in the V3 loop to affect host cells. This process reduces the HIV-1 load and the inflammation caused by opportunistic Gram-negative bacteria. Segmented filamentous bacteria protect against vesicular stomatitis virus, reovirus, influenza $A$, and rotavirus ${ }^{101.96}$. Moreover, viral infectivity can be reduced by bacterial products. For example, surfactin is produced by Bacillus subtilis and can disrupt the virion coronavirus and reduce the infectivity of different enveloped viruses (e.g. Crimean-Congo hemorrhagic fever, Dugbe, Ebola, influenza A, Mayaro, Nipah, Una, Zika, and Chikungunya) ${ }^{102-103}$. The conclusion of current research suggests that $L$. plantarum DR7 may be useful in the treatment of infection due to immunomodulation and release of IFN- $\gamma$, TNF- $\alpha$ pro-inflammatory cytokines ${ }^{104}$. Some studies reveal a significant association between the microbiota composition and the ability of the host immune system to evade viruses. This association could be attributed to the mechanism through which viruses enter a host's system. For example, some viruses enter the host system through mucosal surfaces, and others evade the immune response to establish chronic infections, which could be the case with the new SARSCoV-2 coronavirus. Therefore, although the gut microbiota is associated with several health benefits, these organisms also can interact with pathogens in various modes of transmission and infection to cause disease ${ }^{73}$. Therefore, it seems that the gut microbiota impacts virus invasion via multiple mechanisms. It is recommended that the use of prebiotics, which assist in the growth of probiotic strains might flatten the curve in COVID-1921.

Scientific studies provide significant evidence on the interaction between the microbiota and viruses. Ample proof highlights how microbiota offer host protection against viruses and help regulate the mucosal immune system. Although none of these effects has been proven on the new SARS-CoV-2 virus, it should not outweigh considering this type of action, particularly, when there are probiotics capable of combating other coronavirus strains ${ }^{105}$. Other evidence suggests that these microorganisms also 
influence virus evasion. Therefore, microbiota may promote or limit viral infection, and in other instances they may have no effect at all, because they interact with each infection via different mechanisms ${ }^{106-107}$. It is suggested that increased permeability of the gut wall allows for increased transportation of bacteria to the lung, modifying the bacterial communities in the lung and thus modifying its immune function (Fig. $1)^{63,108}$. Comparisons on recent studies need to be wisely followed. For example, immune system dysregulation in COVID-19 with severe respiratory distress has indeed been reported.

\section{CONCLUSION}

In conclusion, vast research has shown how some microorganisms lead to diseases and others enhance digestion, immunity, and metabolic activities. The microorganisms of the human microbiome play pivotal roles in immune activities and diseases. Development of the microbiota begins in utero and continues throughout life. Its composition and immune effectiveness depend on numerous factors, including the mode of delivery, environmental factors, and diet. The sources of microbiota range from food products to direct consumption of microbes. The possibility that the gut virome is an unidentified player in disease pathways is a plausible idea. Moreover, the human gut virome must be researched and studied in parallel with gut bacterial and fungal diversity. Future studies are necessary to understand better bacteria-virus interactions, cell-to-cell interactions, virus attachment sites, replication and the role probiotics on our gut when fighting against viral infections. Understanding how these microbes interact with disease processes may offer insight into treatment and prevention strategies for many illnesses, such as schizophrenia, autism, and diabetes.

\section{ACKNOWLEDGMENTS}

I would like to thank the Saudi Digital Library for access to the selected publications for free.

\section{FUNDING}

None.

\section{DATA AVAILABILITY}

Not applicable.

\section{ETHICS STATEMENT}

Not applicable.

\section{REFERENCES}

1. Clarke G, Stilling RM, Kennedy PJ, Stanton C, Cryan JF, Dinan TG. Minireview: gut microbiota: the neglected endocrine organ. Mol Endocrinol. 2014;28(8):12211238. doi: 10.1210/me.2014-1108

2. Neuman H, Debelius JW, Knight R, Koren O. Microbial endocrinology: the interplay between the microbiota and the endocrine system. FEMS Microbiol Rev. 2015;39(4):509-521. doi: 10.1093/femsre/fuu010

3. Gensollen T, lyer SS, Kasper DL, Blumberg RS. How colonization by microbiota in early life shapes the immune system. Science. 2016;352(6285):539-544. doi: $10.1126 /$ science.aad9378

4. Ventura M, Milani C, Lugli GA, van Sinderen D. Health benefits conferred by the human gut microbiota during infancy. Microb Biotechnol. 2019;12(2):243-248. doi: 10.1111/1751-7915.13334

5. Forslund K, Hildebrand F, Nielsen T, et al. Disentangling type 2 diabetes and metformin treatment signatures in the human gut microbiota. Nature. 2015;528(7581):262-266. doi: 10.1038/nature15766

6. Mardinoglu A, Boren J, Smith U. Confounding effects of metformin on the human gut microbiome in type 2 diabetes. Cell Metabol. 2016;23(1):10-12. doi: 10.1016/j.cmet.2015.12.012

7. Grasset E, Puel A, Charpentier J, et al. A specific gut microbiota dysbiosis of type 2 diabetic mice induces GLP-1 resistance through an enteric NOdependent and gut-brain axis mechanism. Cell metabolism. 2017;25(5):1075-1090. doi: 10.1016/j. cmet.2017.04.013

8. Liao X, Song L, Zeng B, et al. Alteration of gut microbiota induced by DPP-4i treatment improves glucose homeostasis. EBioMedicine. 2019;44:665-674. doi: 10.1016/j.ebiom.2019.03.057

9. $\mathrm{Yu} X$, Zhang $\mathrm{X}$, Jin $\mathrm{H}$, et al. Zhengganxifeng Decoction Affects Gut Microbiota and Reduces Blood Pressure via Renin-Angiotensin System. Biological and Pharmaceutical Bulletin. 2019;42(9):1482-1490. doi: 10.1248/bpb.b19-00057

10. Jama HA, Kaye DM, Marques FZ. The gut microbiota and blood pressure in experimental models. Curr Opin Nephrol Hyperts. 2019;28(2):97-104. doi: 10.1097/ MNH.0000000000000476

11. Man AW, Xia N, Daiber A, Li H. The roles of gut microbiota and circadian rhythm in the cardiovascular protective effects of polyphenols. Br J Pharmacol. 2020;177(6):1278-1293. doi: 10.1111/bph.14850

12. Kang DW, Adams JB, Coleman DM, et al. Long-term benefit of microbiota transfer therapy on autism symptoms and gut microbiota. Sci Rep. 2019;9(1):5821. doi: 10.1038/s41598-019-42183-0

13. Li $\mathrm{P}$, Zhang $\mathrm{T}$, Xiao $\mathrm{Y}$, et al. Timing for the second fecal microbiota transplantation to maintain the long-term 
benefit from the first treatment for Crohn's disease. Appl Microbiol Biotechnol. 2019;103(1):349-360. doi: 10.1007/s00253-018-9447-x

14. Lima MT, Andrade ACDSP, Oliveira GP, et al. Virus and microbiota relationships in humans and other mammals: An evolutionary view. Human Microbiome Journal. 2019;11:100050. doi: 10.1016/j. humic.2018.11.001

15. Robinson CM, Pfeiffer JK. Viruses and the microbiota. Annu Rev Virol. 2014;1:55-69. doi: 10.1146/annurevvirology-031413-085550

16. Walker FC, Baldridge MT. Interactions between noroviruses, the host, and the microbiota. Curr Opin Virol. 2019;37:1-9. doi: 10.1016/j.coviro.2019.04.001

17. Laforest-Lapointe I, Arrieta MC. Patterns of earlylife gut microbial colonization during human immune development: an ecological perspective. Frontiers in immunology. 2017;8:788. doi: 10.3389/ fimmu.2017.00788

18. Wampach L, Heintz-Buschart A, Hogan A, et al. Colonization and succession within the human gut microbiome by archaea, bacteria, and microeukaryotes during the first year of life. Front Microbiol. 2017;8:738. doi: 10.3389/fmicb.2017.00738

19. Kolodziejczyk AA, Zheng D, Elinav E. Diet-microbiota interactions and personalized nutrition. Nat Rev Microbiol. 2019;17:742-753. doi: 10.1038/s41579019-0256-8

20. Backhed F, Roswall J, Peng $Y$, et al. Dynamics and stabilization of the human gut microbiome during the first year of life. Cell Host Microbe. 2015;17:852 doi:10.1016/j.chom.2015.05.012

21. Gronlund MM, Grzeskowiak L, Isolauri E, Salminen S. Influence of mother's intestinal microbiota on gut colonization in the infant. Gut microbes. 2011;2(4):227-233. doi: 10.4161/gmic.2.4.16799

22. Akagawa $S$, Tsuji $S$, Onuma $C$, et al. Effect of delivery mode and nutrition on gut microbiota in neonates. Ann Nutr Metab. 2019;74(2):132-139. doi: 10.1159/000496427

23. Kim H, Sitarik AR, Woodcroft K, Johnson CC, Zoratti E. Birth mode, breastfeeding, pet exposure, and antibiotic use: associations with the gut microbiome and sensitization in children. Curr Allergy Asthma Rep. 2019;19(4):22. doi: 10.1007/s11882-019-0851-9

24. Nuriel-Ohayon M, Neuman H, Koren O. Microbial changes during pregnancy, birth, and infancy. Front Microbiol. 2016;7:1031. doi: 10.3389/ fmicb.2016.01031

25. Zhou X, Du L, Shi R, Chen Z, Zhou Y, Li Z. Earlylife food nutrition, microbiota maturation and immune development shape life-long health. Crit Rev Food Sci Nutr. 2019;59(sup1):S30-S38. doi: 10.1080/10408398.2018.1485628

26. Yang B, Chen Y, Stanton C, et al. Bifidobacterium and lactobacillus composition at species level and gut microbiota diversity in infants before 6 weeks. Int $\mathrm{J} \mathrm{Mol}$ Sci. 2019;20(13):3306. doi: 10.3390/ijms20133306

27. Liu Z, Luo G, Du R, et al. Effects of spaceflight on the composition and function of the human gut microbiota. Gut Microbes. 2020;11(4):807-819. doi: $10.1080 / 19490976.2019 .1710091$
28. Maqsood R, Rodgers R, Rodriguez C, et al. Discordant transmission of bacteria and viruses from mothers to babies at birth. Microbiome. 2019;7(156). doi: 10.1186/s40168-019-0766-7

29. Jakobsson $H E$, Abrahamsson $T R$, Jenmalm $M C$, et al. Decreased gut microbiota diversity, delayed Bacteroidetes colonisation and reduced Th1 responses in infants delivered by caesarean section. Gut. 2014;63(4):559-566. doi: 10.1136/gutjnl-2012-303249

30. Singh AK, Cabral C, Kumar R, et al. Beneficial effects of dietary polyphenols on gut microbiota and strategies to improve delivery efficiency. Nutrients. 2019;11(9):2216. doi: 10.3390/nu11092216

31. Shao Y, Forster SC, Tsaliki E, et al. Stunted microbiota and opportunistic pathogen colonization in caesareansection birth. Nature. 2019;574(7776):117-121. doi: 10.1038/s41586-019-1560-1

32. Scholtens PA, Oozeer R, Martin R, Amor KB, Knol J. The early settlers: intestinal microbiology in early life. Ann Rev Food Sci Tech. 2012;3:425-447. doi: 10.1146/ annurev-food-022811-101120

33. Munyaka PM, Khafipour E, Ghia JE. External influence of early childhood establishment of gut microbiota and subsequent health implications. Frontiers in Pediatrics. 2014;2:109. doi: 10.3389/fped.2014.00109

34. Zhuang L, Chen $\mathrm{H}$, Zhang S, Zhuang J, Li Q, Feng Z. Intestinal microbiota in early life and its implications on childhood health. Genomics, Proteomics \& Bioinformatics. 2019;17(1):13-25. doi: 10.1016/j. gpb.2018.10.002

35. Borewicz K, Gu F, Saccenti E, et al. Correlating Infant Fecal Microbiota Composition and Human Milk Oligosaccharide Consumption by Microbiota of 1Month-Old Breastfed Infants. Mol Nutr Food Res. 2019;63(13):1801214. doi: 10.1002/mnfr.201801214

36. Kumar A, Chordia N. Role of microbes in human health. Appl Microbiol. 2017;3:2. doi: 10.4172/24719315.1000131

37. Rinninella $E$, Raoul $P$, Cintoni $M$, et al. What is the healthy gut microbiota composition? A changing ecosystem across age, environment, diet, and diseases. Microorganisms. 2019;7(1):14. doi: 10.3390/ microorganisms7010014

38. Derrien M, Alvarez AS, de Vos WM. The gut microbiota in the first decade of life. Trends in Microbiology. 2019;27(12):997-1010. doi: 10.1016/j.tim.2019.08.001

39. Zmora N, Suez J, Elinav E. You are what you eat: Diet, health and the gut microbiota. Nat Rev Gastroenterol Hepatol. 2019;16(1):35-56. doi: 10.1038/s41575-0180061-2

40. Gao L, Xu T, Huang G, Jiang S, Gu Y, Chen F. Oral microbiomes: More and more importance in oral cavity and whole body. Protein \& Cell. 2018;9(5):488-500. doi: 10.1007/s13238-018-0548-1

41. Mosaddad SA, Tahmasebi E, Yazdanian A, Rezvani MB, Seifalian A, Yazdanian M, Tebyanian H. Oral microbial biofilms: an update. Eur J Clin Microbiol Infect Dis. 2019;38:2005-2019. doi: 10.1007/s10096-019-036419

42. Luti KJK. Bacteriocin production by Staphylococcus epidermidis the normal flora of outer ear: a potential probiotic against outer ear infections. Journal of 
Biotech Research. 2020;11:13-22.

43. $\mathrm{Xu} \mathrm{H}, \mathrm{Li} \mathrm{H}$. Acne, the skin microbiome, and antibiotic treatment. Am J Clin Dermatol. 2019;20(3):335-344 doi: 10.1007/s40257-018-00417-3

44. Wojewodzic MW. Bacteriophages could be a potential game changer in the trajectory of coronavirus disease (COVID-19). PHAGE. 2020;1(2):60-65. doi: 10.1089/ phage.2020.0014

45. Biram A, Shulman Z. T cell help to B cells: Cognate and atypical interactions in peripheral and intestinal lymphoid tissues. Immunol Rev. 2020:296(1):36-47 doi: $10.1111 / \mathrm{imr} .12890$

46. Metzger RN, Krug $A B$, Eisenacher K. Enteric virome sensing-its role in intestinal homeostasis and immunity. Viruses. 2018;10(4):146. doi: 10.3390/v10040146

47. Khaneghah AM, Abhari K, Es I, et al. Interactions between probiotics and pathogenic microorganisms in hosts and foods: A review. Trends Food Sci Tech. 2020;95:205-218. doi: 10.1016/j.tifs.2019.11.022

48. Li XY, He C, Zhu Y, Lu NH. Role of gut microbiota on intestinal barrier function in acute pancreatitis. World J Gastroenterol. 2020;26(18):2187-2193. doi: 10.3748/ wjg.v26.i18.2187

49. Claus SP, Guillou H, Ellero-Simatos S. The gut microbiota: A major player in the toxicity of environmental pollutants? Npj Biofilms and Microbiomes. 2016;2:16003. doi: 10.1038/npjbiofilms.2016.3

50. Cani PD, Van Hul M, Lefort C, Depommier C, Rastelli $M$, Everard A. Microbial regulation of organismal energy homeostasis. Nat Metab. 2019;1(1):34-46. doi: 10.1038/s42255-018-0017-4

51. Zaiss MM, Jones RM, Schett G, Pacifici R. The gut-bone axis: how bacterial metabolites bridge the distance. J Clin Invest. 2019;129(8):3018-3028. doi: 10.1172/ $\mathrm{JCl} 128521$

52. Bartman C, Chong AS, Alegre ML. The influence of the microbiota on the immune response to transplantation. Curr Opin Organ Transplant. 2015;20(1):1-7. doi: 10.1097/MOT.0000000000000150

53. Thursby $\mathrm{E}$, Juge N. Introduction to the human gut microbiota. Biochemical Journal. 2017;474(11):18231836. doi: 10.1042/BCJ20160510

54. Belkaid $Y$, Tamoutounour S. The influence of skin microorganisms on cutaneous immunity. Nat Rev Immunol. 2016;16(6):353-366. doi: 10.1038/ nri.2016.48

55. He $Y$, Wen $Q$, Yao F, Xu D, Huang $Y$, Wang J. Gutlung axis: the microbial contributions and clinical implications. Crit Rev Microbiol. 2017;43(1):81-95. doi: 10.1080/1040841X.2016.1176988

56. Hu Y, Xie G, Jiang X, Shao K, Tang X, Gao G. The relationships between the free-living and particleattached bacterial communities in response to elevated eutrophication. Front Microbiol. 2020;11:423. doi: 10.3389/fmicb.2020.00423

57. Wang B, Yao M, Lv L, Ling Z, Li L. The human microbiota in health and disease. Engineering. 2017;3(1):71-82. doi: 10.1016/J.ENG.2017.01.008

58. Zheng W, He R, Yan Z, et al. Regulation of immunedriven pathogenesis in Parkinson's disease by gut microbiota. Brain, Behavior, and Immunity. 2020:87:890-897. doi: 10.1016/j.bbi.2020.01.009
59. Sgritta M, Dooling SW, Buffington SA, et al. Mechanisms underlying microbial-mediated changes in social behavior in mouse models of autism spectrum disorder. Neuron. 2019;101(2):246-259. doi: 10.1016/j. neuron.2018.11.018

60. Moreno I, Simon C. Deciphering the effect of reproductive tract microbiota on human reproduction. Reprod Med Biol. 2019;18(1):40-50. doi: 10.1002/ rmb2.12249

61. Bell JS, Spencer JI, Yates RL, Yee SA, Jacobs BM, DeLuca GC. Invited Review: From nose to gut-the role of the microbiome in neurological disease. Neuropathol Appl Neurobiol. 2019;45(3):195-215. doi: 10.1111/ nan. 12520

62. Fanos V, Pintus MC, Pintus R, Marcialis MA. Lung microbiota in the acute respiratory disease: from coronavirus to metabolomics. J Pediatr Neonat Individ. Med. 2020;9:e090139. doi: 10.7363/090139

63. Jia J, Xun P, Wang X, et al. Impact of Postnatal Antibiotics and Parenteral Nutrition on the Gut Microbiota in Preterm Infants During Early Life. J Parenter Enteral Nutr. 2020;44(4):639-654. doi: 10.1002/jpen.1695

64. Le Doare K, Holder B, Bassett A, Pannaraj PS. Mother's milk: A purposeful contribution to the development of the infant microbiota and immunity. Front Immunol. 2018;9:361. doi: 10.3389/fimmu.2018.00361

65. Asto E, Mendez I, Audivert S, Farran-Codina A, Espadaler J. The efficacy of probiotics, prebiotic inulintype fructans, and synbiotics in human ulcerative colitis: a systematic review and meta-analysis. Nutrients. 2019;11(2):293. doi: 10.3390/nu11020293

66. Vieira TF, Correa RCG, Peralta RA, et al. An Overview of Structural Aspects and Health Beneficial Effects of Antioxidant Oligosaccharides. Current Pharmaceutical Design. 2020;26(16):1759-1777. doi: 10.2174/138161 2824666180517120642

67. Gyawali R, Nwamaioha N, Fiagbor R, Zimmerman T, Newman RH, Ibrahim SA. The role of prebiotics in disease prevention and health promotion. In Dietary Interventions in Gastrointestinal Diseases. Academic Press. 2019:151-167. doi: 10.1016/B978-0-12-8144688.00012-0

68. Mukhopadhya I, Segal JP, Carding SR, Hart AL, Hold GL. The gut virome: the 'missing link'between gut bacteria and host immunity?. Therap Adv Gastroenterol. 2019;12:1-17. doi: 10.1177/1756284819836620

69. Davani-Davari D, Negahdaripour M, Karimzadeh I, et al. Prebiotics: definition, types, sources, mechanisms, and clinical applications. Foods. 2019;8(3):92. doi: 10.3390/foods8030092

70. Lindsay JO, Whelan K, Stagg AJ, et al. Clinical, microbiological, and immunological effects of fructooligosaccharide in patients with Crohn's disease. Gut. 2006;55(3):348-355. doi: 10.1136/gut.2005.074971

71. Prabhurajeshwar C, Chandrakanth K. Evaluation of antimicrobial properties and their substances against pathogenic bacteria in-vitro by probiotic Lactobacilli strains isolated from commercial yoghurt. Clinical Nutrition Experimental. 2019;23:97-115. doi: 10.1016/j.yclnex.2018.10.001

72. Lam KL, Cheung PCK. Carbohydrate-based prebiotics in targeted modulation of gut microbiome. J Agric Food 
Chem. 2019;67(45):12335-12340. doi: 10.1021/acs. jafc.9b04811

73. Plaza-Diaz J, Ruiz-Ojeda FJ, Gil-Campos M, Gil A. Mechanisms of Action of Probiotics. Advances in Nutrition. 2019;10(suppl_1):S49-S66. doi: 10.1093/ advances/nmy063

74. Bianchini S, Orabona C, Camilloni B, et al. Effects of probiotic administration on immune responses of children and adolescents with type 1 diabetes to a quadrivalent inactivated influenza vaccine. Hum Vaccin Immunother. 2020;16(1):86-94. doi: 10.1080/21645515.2019.1633877

75. Sanidad KZ, Zeng MY. Neonatal gut microbiome and immunity. Curr Opin Microbiol. 2020;56:30-37. doi: 10.1016/j.mib.2020.05.011

76. Rodriguez JM, Murphy $\mathrm{K}$, Stanton $\mathrm{C}$, et al. The composition of the gut microbiota throughout life, with an emphasis on early life. Microbial Ecology in Health and Disease. 2015;26(1):26050. doi: 10.3402/ mehd.v26.26050

77. Dominguez-Bello MG, Godoy-Vitorino F, Knight $R$, Blaser MJ. Role of the microbiome in human development. Gut. 2019;68(6):1108-1114. doi: 10.1136/gutjnl-2018-317503

78. Antosca KM, Chernikova DA, Price CE, et al. Altered stool microbiota of infants with cystic fibrosis shows a reduction in genera associated with immune programming from birth. J Bacteriol. 2019;201(16):e00274-19. doi: 10.1128/JB.00274-19

79. Ficara M, Pietrella E, Spada C, et al. Changes of intestinal microbiota in early life. J Matern Fetal Neonatal Med. 2020;33(6):1036-1043. doi: 10.1080/14767058.2018.1506760

80. Quin C, Gibson DL. Human behavior, not race or geography, is the strongest predictor of microbial succession in the gut bacteriome of infants. Gut Microbes. 2020;11(5):1143-1171. doi: 10.1080/19490976.2020.1736973

81. Sovran B, Hugenholtz F, Elderman M, et al. Ageassociated impairment of the mucus barrier function is associated with profound changes in microbiota and immunity. Sci Rep. 2019;9:1437. doi: 10.1038/s41598-018-35228-3

82. Cox LM, Schafer MJ, Sohn J, et al. Calorie restriction slows age-related microbiota changes in an Alzheimer's disease model in female mice. Sci Rep. 2019;9:17904. doi: 10.1038/s41598-019-54187-x

83. Czepiel J, Drozdz M, Pituch $\mathrm{H}$, et al. Clostridium difficile infection. Eur J Clin Microbiol Infect Dis. 2019;38:12111221. doi: 10.1007/s10096-019-03539-6

84. Caupenne A, Ingrand P, Ingrand I, Forestier E, RoubaudBaudron C, Gavazzi G, Paccalin M. Acute Clostridioides difficile infection in hospitalized persons aged 75 and older: 30-day prognosis and risk factors for mortality. $J$ Am Med Dir Assoc. 2020;21(1):110-114. doi: 10.1016/j. jamda.2019.07.002

85. Ribaldone DG, Caviglia GP, Abdulle A, et al. Adalimumab therapy improves intestinal dysbiosis in Crohn's disease. J Clin Med. 2019;8(10):1646. doi: 10.3390/ jcm8101646

86. Lavoie S, Conway KL, Lassen KG, et al. The Crohn's disease polymorphism, ATG16L1 T300A, alters the gut microbiota and enhances the local Th1/Th17 response. Elife. 2019;8:e39982. doi: $10.7554 /$ eLife. 39982

87. $\mathrm{Xu} \mathrm{R}, \mathrm{Wu} \mathrm{B}$, Liang J, et al. Altered gut microbiota and mucosal immunity in patients with schizophrenia. Brain, Behavior, and Immunity. 2020:85:120-127.doi: 10.1016/j.bbi.2019.06.039

88. Cuomo A, Maina G, Rosso G, et al. The microbiome: A new target for research and treatment of schizophrenia and its resistant presentations? A systematic literature search and review. Front Pharmacol. 2018;9:1040. doi: 10.3389/fphar.2018.01040

89. Carlessi AS, Borba LA, Zugno Al, Quevedo J, \& Reus GZ. Gut microbiota-brain axis in depression: The role of neuroinflammation. Eur J Neurosci. 2021:53(1):222235. doi: 10.1111/ejn.14631

90. Liu S, Li E, Sun Z, et al. Altered gut microbiota and short chain fatty acids in Chinese children with autism spectrum disorder. Sci Rep. 2019;9(1):287. doi: 10.1038/s41598-018-36430-z

91. Kanashiro A, Hiroki CH, da Fonseca DM, et al. The role of neutrophils in neuro-immune modulation. Pharmacol Res. 2020;151:104580. doi: 10.1016/j. phrs.2019.104580

92. Fattorusso A, Di Genova L, Dell'Isola GB, Mencaroni E, Esposito $S$. Autism spectrum disorders and the gut microbiota. Nutrients. 2019;11(3):521. doi: 10.3390/ nu11030521

93. Al-Assal K, Martinez AC, Torrinhas RS, Cardinelli C, Waitzberg D. Gut microbiota and obesity. Clinical Nutrition Experimental. 2018;20:60-64. doi: 10.1016/j. yclnex.2018.03.001

94. Abenavoli L, Scarpellini E, Colica C, et al. Gut microbiota and obesity: a role for probiotics. Nutrients. 2019;11(11):2690. doi: 10.3390/nu11112690

95. Kalantar-Zadeh K, Ward SA, Kalantar-Zadeh K, ElOmar EM. Considering the Effects of Microbiome and Diet on SARS-CoV-2 Infection: Nanotechnology Roles. ACS nano. 2020:14(7):9202. doi: 10.1021/ acsnano.0c04407

96. Dhar D, Mohanty A. Gut microbiota and Covid-19possible link and implications. Virus Res. 2020;285:198018. doi: 10.1016/j.virusres.2020.198018

97. Cevik M, Bamford C, Ho A. COVID-19 pandemic-a focused review for clinicians. Clin Microbiol Infect. 2020:26(7):842-847. doi: 10.1016/j.cmi.2020.04.023

98. Kopel J, Perisetti A, Gajendran M, Boregowda U, Goyal H. Clinical insights into the gastrointestinal manifestations of COVID-19. Dig Dis Sci. 2020;65:19321939. doi: 10.1007/s10620-020-06362-8

99. Olaimat AN, Aolymat I, Al-Holy M, et al. The potential application of probiotics and prebiotics for the prevention and treatment of COVID-19. NPJ Science of Food. 2020;4,17. doi: 10.1038/s41538-020-00078-9

100. Majerle A, Pristovsek P, Mancek-Keber M, Jerala R. Interaction of the HIV-1 gp120 Viral Protein V3 Loop with Bacterial Lipopolysaccharide A PATTERN RECOGNITION INHIBITION. Journal of Biological Chemistry. 2011;286(29):26228-26237. doi: 10.1074/ jbc.M111.220434

101. Neu U, Mainou BA. Virus interactions with bacteria: Partners in the infectious dance. PLoS Pathogens. 
2020;16(2):e1008234. doi: 10.1371/journal. ppat.1008234

102. Buzon MJ, Seiss K, Weiss R, et al. Inhibition of HIV-1 integration in ex vivo-infected CD4 T cells from elite controllers. J Virol. 2011;85(18):9646-9650. doi: 10.1128/JVI.05327-11

103. Cochrane SA, Vederas JC. Lipopeptides from Bacillus and Paenibacillus spp.: a gold mine of antibiotic candidates. Med Res Rev. 2016;36(1):4-31. doi: 10.1002/med.21321

104. Chong HX, Yusoff NAA, Hor YY, et al. Lactobacillus plantarum DR7 improved upper respiratory tract infections via enhancing immune and inflammatory parameters: A randomized, double-blind, placebo-controlled study. Journal of dairy science. 2019;102(6):4783-4797. doi: 10.3168/jds.2018-16103
105. Kumar R, Seo BJ, Mun MR, et al. Putative probiotic Lactobacillus spp. from porcine gastrointestinal tract inhibit transmissible gastroenteritis coronavirus and enteric bacterial pathogens. Trop Anim Health Prod. 2010;42:1855-1860. doi: 10.1007/s11250-010-9648-5

106. Rowan -Nash AD, Korry BJ, Mylonakis E, Belenky P. Cross-domain and viral interactions in the microbiome. Microbiol Mol Biol Rev. 2019;83(1):e00044-18. doi: 10.1128/MMBR.00044-18

107. Cheng HY, Ning MX, Ma WT, Chen DK. Interactions between the gut microbiota and the host innate immune response against pathogens. Front Immunol. 2019;10:607. doi: 10.3389/fimmu.2019.00607

108. He LH, Ren LF, Li JF, et al. Intestinal flora as a potential strategy to fight SARS-CoV-2 infection. Front Microbiol. 2020;11:1388. doi: 10.3389/fmicb.2020.01388 